Mar. Drugs 2006, 4, 228-254

Marine Drugs

ISSN 1660-3397

(C) 2006 by MDPI

www.mdpi.org/marinedrugs

Special Issue on “Marine Drugs and Ion Channels” Edited by Hugo Arias

Review

\title{
The Chemistry and Pharmacology of Anatoxin-a and Related Homotropanes with respect to Nicotinic Acetylcholine Receptors
}

\author{
Susan Wonnacott ${ }^{1, *}$ and Timothy Gallagher ${ }^{2}$ \\ ${ }^{1}$ Department of Biology and Biochemistry, University of Bath, Bath BA2 7AY, United Kingdom \\ E-mail: bsssw@bath.ac.uk \\ ${ }^{2}$ School of Chemistry, University of Bristol, Bristol BS8 1TS, United Kingdom \\ E-mail: T.Gallagher@bristol.ac.uk
}

* Author to whom correspondence should be addressed.

Received: 25 January 2006 / 31 January 2006 / Published: 6 April 2006

\begin{abstract}
This chapter covers the chemistry and nicotinic pharmacology of naturally occurring homotropane alkaloids, with an emphasis of anatoxin-a. In addition to anatoxin-a, homoanatoxin and pinnamine, as well as the major classes of synthetic derivatives of anatoxin-a including UB-165, are discussed.
\end{abstract}

Keywords: anatoxin-a, homoanatoxin, UB165, pinnamine, homotropane, nicotinic acetylcholine receptor, pharmacophore

Abbreviations: nAChR, nicotinic acetylcholine receptors; PHT, pyrido[3,4-b]-homotropane; QSAR, quantitative structure activity relationship; VDW, van der Waals.

\section{Introduction}

This chapter aims to cover the chemistry and nicotinic pharmacology of naturally occurring homotropane alkaloids and their synthetic derivatives, with particular emphasis on anatoxin-a - first isolated from freshwater algae and the ligand in this group that has attracted the most attention because of its specificity and potency as an agonist at nicotinic acetylcholine receptors (nAChR). The core homotropane moiety consists of a unsymmetrical bicyclic arrangement (the 9-azabicyclo[4.2.1]nonane) based on two and four-carbon bridges and incorporating a secondary amine (Figure 1). Homotropanes are one-carbon homologues of the tropane ring system, the best known example of which is cocaine 
(see Figure 2), and there are some important relationships between tropane and homotropane alkaloids that are described below.

The toxic impact associated with the homotropane-based natural products themselves, together with the need to develop sensitive analytical methods for the detection of these toxins in water supplies, provided the initial focus for the pharmacologist and chemist [1]. A good deal of work has also been done to define effective analytical methods to detect and determine anatoxin-a, homoanatoxin and a range of their metabolites, and the reader is referred to a series of recent reviews for further discussion of analytical methods and natural sources of anatoxin-a and homoanatoxin [2-5].

Subsequently, synthetic modifications of the parent molecules have generated a diverse array of structural analogues for investigative research. Much of this chemistry has been driven by the development of syntheses of the naturally-occurring alkaloids themselves. These studies have an intrinsic value in the development of the chemical science, but the diversity and complementary nature of the resultant synthetic strategies provides an entry to a wide variety of structural variation [6]. This has facilitated examination of questions such as the bioactive conformation and quantitative structure activity relationship (QSAR) of anatoxin-a and other nicotinic ligands, as well as generating potent research tools for the study of nAChR. This combination of synthetic chemistry and pharmacology has, in turn, contributed towards the refinement of pharmacophore models to address nAChR subtype diversity.

\section{The Nicotinic Acetylcholine Receptor (nAChR)}

nAChR comprise a family of ligand-gated cation channel receptors expressed in the central and peripheral nervous systems and responsive to the neurotransmitter acetylcholine. nAChR mediate neuromuscular transmission, and these receptors were the first to be purified, cloned and characterised [7]. The muscle nAChR is comprised of 5 subunits, arranged like staves of a barrel around a central pore. The muscle nAChR subunits are designated $\alpha, \beta, \gamma$ and $\delta$, with two copies of the $\alpha$ subunit. At mature muscle endplates, the $\gamma$ subunit is replaced by $\varepsilon$. The binding sites for acetylcholine reside predominantly on the $\alpha$ subunits, they are formed by non-contiguous loops of amino acids that create a physical pocket and opportunities for chemical interactions. Additional amino acid residues from the adjacent subunit also contribute to acetylcholine or agonist binding, so that the non- $\alpha$ subunits can influence agonist affinity or selectivity, making the two binding sites in muscle nAChR non-identical [7]. Affinity labelling strategies have identified five highly conserved aromatic residues (tyrosine and tryptophan) that have been proposed to stabilise the protonated nitrogen of agonists, through $\pi$ interactions. Conserved aspartate residues provide the probable source of negative electrostatic potential for hydrogen bonding to other pharmacophoric elements of nicotinic agonists (see later).

Agonist binding results in a conformational change that opens the integral ion channel, leading to the flow of cations; $\mathrm{Na}^{+}$(and also $\mathrm{Ca}^{2+}$ ) typically enters the cell. Anatoxin-a first attracted attention as a tool for investigating muscle nAChR because it closely mimics acetylcholine in its activation of the nAChR, but lacks the complications of muscarinic activity and susceptibility to enzymatic or chemical hydrolysis. [8] Although influenced by the nature of the agonist, the duration of channel opening is an intrinsic property of the nAChR subtype and the channel will close automatically to enter a refractive or desensitised state, becoming unavailable for further activation for a period of time. The prolonged presence of agonist will sustain the desensitised state. It is likely that the toxic effects of anatoxin-a are 
primarily exerted through binding to the muscle nAChR, with prolonged interaction resulting in desensitisation blockade and muscle paralysis leading to respiratory failure [9].

In recent years, research has focussed on neuronal nAChR expressed in the central and peripheral nervous systems. As a secondary amine, anatoxin-a can cross the blood brain barrier to interact with central nAChR in vivo [10,11]. Neuronal nAChR are assembled from a portfolio of distinct subunits from those found in muscle: at least 9 subunits $(\alpha 2-\alpha 7 ; \beta 2-\beta 4)$ have been reported to be expressed in various mammalian CNS neurones, raising the prospect of a great diversity of nAChR subtypes that may differ in their pharmacological specificity, channel kinetics, temporal, regional and subcellular expression patterns etc. Both heteromeric nAChR, comprised of $\alpha$ and $\beta$ subunits (e.g. $\alpha 4 \beta 2 *$ nAChR, where * indicates the possible presence of additional types of subunit, [12]) and homomeric nAChR (comprised of five $\alpha 7$ subunits) occur in nervous tissue, and anatoxin-a potently activates both classes of $\mathrm{nAChR}\left(\mathrm{EC}_{50}\right.$ at $\alpha 4 \beta 2=48 \mathrm{nM} ; \mathrm{EC}_{50}$ at $\alpha 7=0.6 \mu \mathrm{M}$ [13]). Neuronal $\mathrm{nAChR}$ have been comprehensively reviewed recently [14] and the reader is referred to this text for details.

$\mathrm{nAChR}$ are also present in invertebrate nervous systems and anatoxin-a interacts with nAChR in insect brain, where these receptors constitute the major excitatory system [15]. In the mammalian brain, however, nAChR serve a predominantly modulatory function [16] and they have attracted the interest of the pharmaceutical industry, as targets for therapeutic intervention in a number of diverse conditions, including neurodegenerative diseases, schizophrenia, epilepsy, anxiety and attention deficit disorder [17]. In addition to a preference for centrally occurring nAChR over muscle and peripheral nAChR (to avoid side effects), it has generally been assumed that subtype selectivity for particular neuronal nAChR subtypes is a desirable attribute of potential therapeutic ligands. However, nAChR subtype discrimination by agonists has been hard to achieve and a rational basis for selective agonist design has been lacking. This highlights the need for subtype-specific pharmocophore models and it is in this capacity that anatoxin-a and its cogeners have been particularly influential.

\section{The Homotropane Alkaloids.}

\section{Isolation, Biosynthesis and Analytical Methods}

The two pharmacologically most important naturally-occurring homotropane nicotinic agonists are anatoxin-a 1 [9,18] and homoanatoxin 2 [19,20,21] (Figure 1), and these alkaloids, together with their derivatives, form the primary focus of this review. However to date, both of these molecules have only been isolated from freshwater sources. The isolation in 2000 of pinnamine $\mathbf{3}$ from the bivalve Pinna muricata represents the only example so far of a homotropane derived from the marine environment [22]. Synthetic entries to pinnamine, with potential to generate novel analogues, have already been published [23,24]. Little has yet appeared on the pharmacology of pinnamine and its derivatives but pinnamine shows a similar toxicity to anatoxin-a (pinnamine $\mathrm{LD}_{99}$ (ip, mouse) $=0.5$ mg.kg ${ }^{-1}$; anatoxin-a $\mathrm{LD}_{50}$ (ip, mouse) $=0.2 \mathrm{mg} \mathrm{kg}^{-1}$ ) [22,25]. Moreover, its structural relationship to anatoxin-a (see Figure 1) impacts on our understanding of conformation vs. bioactivity and this is discussed below.

Three other naturally occurring alkaloids with nicotinic agonist activity, epibatidine $\mathbf{5}$, ferrunginine 6 and nicotine $\mathbf{7}$ merit mention although It is important to appreciate that these are not homotropane 
alkaloids and so not a focus for this review. There is a clear structural relationship between anatoxin-a $\mathbf{1}$ and ferrunginine $\mathbf{6}$ (which is tropane based) and important links between anatoxin-a $\mathbf{1}$ and epibatidine 4, and anatoxin-a $\mathbf{1}$ and nicotine $\mathbf{7}$ will be discussed.

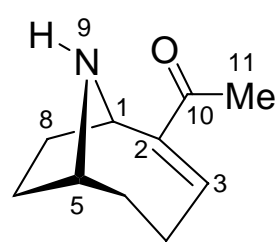

(+)-Anatoxin-a 1

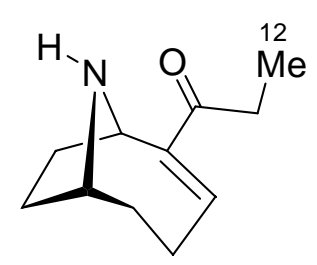

Homoanatoxin 2

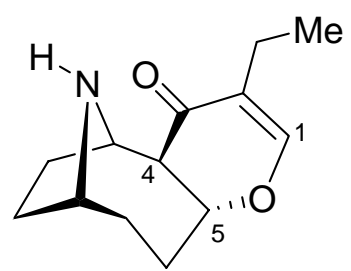

(+)-Pinnamine 3

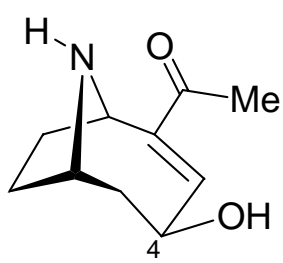

4-Hydroxyanatoxin-a 4

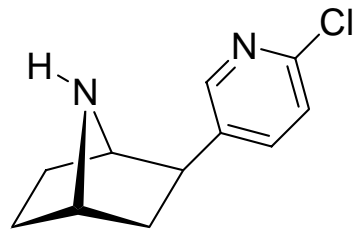

(-)-Epibatidine 5

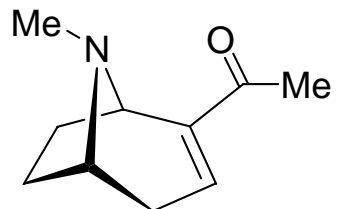

(-)-Ferrunginine 6

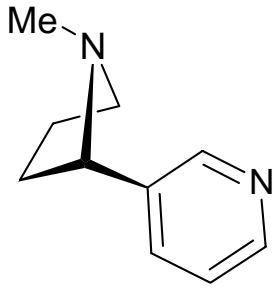

(-)-Nicotine 7

Figure 1. Naturally-occurring homotropane alkaloids and related nicotinic ligands. Note: the numbering systems used in this review are indicated on the structures shown above.

Anatoxin-a 1 is produced by toxic strains of the cyanobacteria Anabaena flos-aquae [9]. Interest in this area was fuelled by the widespread and well recorded incidents of the poisoning, usually fatal, of wild and domestic animals associated with blooms of cyanobacteria in North America and in Europe; anatoxin-a was initially referred to VFDF (very fast death factor). The isolation of anatoxin-a $\mathbf{1}$ from Anabaena flos-aquae was first reported in the mid-1970's [18], although the crystal structure of anatoxin-a (as the $N$-acetyl derivative) had already been solved by 1972 [26]. Anatoxin-a has subsequently been isolated from toxic strains of Oscillatoria, Anabaena circinalis, Aphanizomenon flos-aquae, Cylindorsperum pp. and Raphidiopsis mediterranea.

The other significant homotropane alkaloid in this class is homoanatoxin $\mathbf{2}$ (sometimes referred to as homoanatoxin-a). The history of homoanatoxin is interesting as this molecule was first reported as a synthetic analogue of anatoxin-a [19]. Only subsequent to its chemical synthesis and characterization was homoanatoxin isolated from the cyanobacterium Oscillatoria Formosa and, more recently, from Raphidiopsis mediterranea where it occurs with minor amounts of anatoxin-a and another homotropane, (4S) 4-hydroxyanatoxin-a 4 [27,28]. This oxygenated variant of anatoxin-a is not toxic, but this and related molecules (e.g. 4-ketoanatoxin-a, epoxyanatoxin-a and dihydroanatoxin-a (see below), and the analogous homoanatoxin variants) are often encountered as degradation by-products of the primary toxic metabolites. These metabolites result from environmental (oxygen and light mediated) degradation and often represent important analytical biomarkers for toxic events that are detectable even when the toxic components themselves are no longer present. It should also be 
pointed out that anatoxin-a(s) is a structurally quite distinct algal-derived toxin that is an acetylcholinesterase inhibitor; anatoxin-a(s) is not a homotropane and will not be considered further.

The biosynthesis of both anatoxin-a and homoanatoxin have been studied extensively using feeding experiments involving radiolabelled precursors [27-31]. The homotropane scaffold of anatoxin-a is derived from glutamic acid (or ornithine), with the $C(1)$ carboxylic acid of glutamate being retained within the carbon skeleton of anatoxin-a; this is a difference between the biosynthetic pathways associated with the tropane and homotropane alkaloids. The remainder of the carbon skeleton is derived from acetate, and the $C(12)$ methyl group of homoanatoxin is derived from $S$ methylmethionine.

\section{Homotropane Alkaloids as Nicotinic Ligands.}

The structure of the homotropane alkaloids.

Molecules such as anatoxin-a combine the semi-rigid template associated with the bicyclic homotropane moiety with a conformationally mobile side chain. Both subunits incorporate elements critical to biological activity - the secondary amine of the homotropane and the carbonyl unit associated with the side chain of anatoxin-a respectively - and this combination of rigidity with flexibility is attractive for probing the spatial as well as chemical requirements for effective binding and nAChR activation.

The structure of anatoxin-a was determined initially by crystallographic methods using the $N$ acetamide derivative [26] and then using synthetic anatoxin-a (as the hydrochloride salt) [32]. These data provide important structural information, but one cannot necessarily extrapolate the solid state structure to the solution conformation or bioactive conformation of a ligand (see below).

Anatoxin-a is a chiral compound with asymmetric centres at C(1) and (5) (Figure 1) and only one enantiomer has to date been reported from natural sources. The first synthesis of anatoxin-a was achieved by Edwards using (-)-cocaine as the starting material, which also served to assign the absolute configuration of natural (+)-anatoxin-a (via correlation with (-)-cocaine) [33]. More recently, an alternative method of the synthesis of $(+)$-anatoxin starting from (-)-cocaine has been reported by Seitz [34], which was based on the earlier work of Trudell [35]. As with Edwards' work, this required a ring expansion reaction to convert the tropane framework of cocaine to the homotropane arrangement present in anatoxin-a and involves ketone $\mathbf{8}$ as a key intermediate (Figure 2). Cocaine provides an efficient synthetic starting point to $(+)$-anatoxin-a and Seitz has utilized this chemistry to produce a range of interesting and biologically active analogues of anatoxin-a, which are discussed in more detail below.

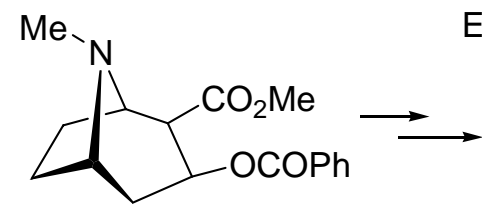

$(-)$-Cocaine

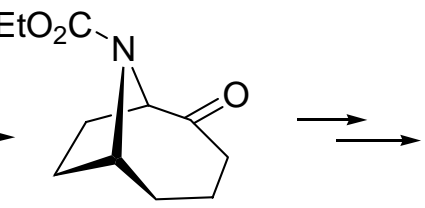

8

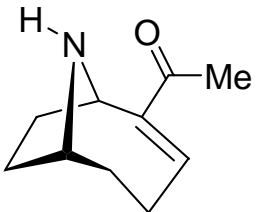

(+)-Anatoxin-a 1

Figure 2. Correlation of (-)-cocaine with (+)-anatoxin-a. Determining the absolute configuration of $(+)$-anatoxin-a. 
Initial comparisons of $(+)$-anatoxin-a with the racemic mixture found that the natural toxin was 2-3 times more potent in activating muscle nAChR, suggesting that (-)-anatoxin-a is inert [36]. This was confirmed following synthesis of (-)-anatoxin-a: the weak activity of the unnatural enantiomer (ent-1) is readily explained by trace contamination with (+)-anatoxin-a. For example, at rat brain nAChR binding sites labelled by $\left[{ }^{3} \mathrm{H}\right]$ nicotine (that predominantly labels $\alpha 4 \beta 2 *$ nAChR under the experimental conditions of a ligand binding assay) the $\mathrm{IC}_{50}$ of (+)-1 is $0.34 \mathrm{nM}$ versus $390 \mathrm{nM}$ for (-)ent-1 9 [15]. This enantiospecific profile is of significance in relation to other nicotinic agonists: both enantiomers of epibatidine 5 are essentially equipotent [37], whereas enantiomers of nicotine are equally effective at muscle nAChR but neuronal $\alpha 4 \beta 2 *$ nAChR show a marked preference for the natural enantiomer (-)-nicotine [38,39]. The relationship between anatoxin-a and epibatidine is also explored later in this chapter.

The structure of homoanatoxin 2 follows from anatoxin-a itself, although only racemic material has been synthesised to date [19]. The structure and absolute configuration of pinnamine $\mathbf{3}$ were determined by a combination of spectroscopic means and asymmetric synthesis [22,23].

Understanding the relationship between chemical structure and pharmacological profile. The nicotinic pharmacophore

Correlation of ligand structure with its nicotinic profile is the challenge that drives the quest for a reliable predictive model, or 'pharmacophore', to rationalise the search for therapeutically useful agents. A pharmacophore represents those components within a ligand's molecular structure that are essential for agonist activity, i.e. recognition and transduction of binding into channel opening. These components may possess a range of properties, such as charge, hydrogen bonding donor or acceptor capabilities, or an ability to interact with, for example, a $\pi$-bond system. The task of correlating such features with a diverse set of structures is simplified by studying comparatively rigid molecules, because these offer fewer conformational options. Anatoxin-a, nicotine, epibatidine and cytisine each comprise a relatively rigid molecular framework with only one (or in the case of cytisine, no) freely rotatable bond, compared with acetylcholine, which with four rotatable bonds is subject to minimal conformational constraints.

In the case of anatoxin-a, the major conformational "uncertainty" is associated with the bond between $C(2)$ and $C(10)$ which can rotate freely leading to two major conformational categories: the $s$ cis and s-trans arrangements (Figure 3). These terms refer to the cisoid vs. transoid relationship between the $\mathrm{C}=\mathrm{C}$ and $\mathrm{C}=\mathrm{O}$ conjugated $\pi$-systems. Interestingly, the crystal structure of anatoxin-a shows only the s-trans form to be present.

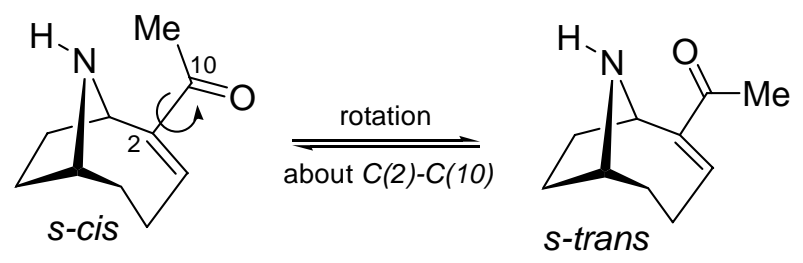

Figure 3. Conformational relationship between s-cis and s-trans anatoxin-a. 
There are some conformational options open to the azabicyclic unit $(C(1)-C(8))$ of anatoxin-a but this nevertheless remains a relatively inflexible part of the overall structure. The relationship between the s-cis and s-trans conformers of anatoxin-a is significant in terms of defining the bioactive conformation of the ligand, and given that this has the potential to make a significant impact on pharmacophore design, this topic has attracted a lot of interest. We will deal with the specifics of this question later, but it is necessary first to review briefly the evolution of models of the nicotinic pharmacophore.

In 1970, Beers and Reich [40] were the first to suggest a pharmacophore model for the nAChR, and proposed that there were two structural elements within a ligand that were essential for nicotinic activity. These were (i) the presence of a cationic center (a protonatable amine or quaternary ammonium) which was essential to maintain a Columbic interaction with the receptor and (ii) a heteroatom (e.g. the pyridine nitrogen of nicotine or the carbonyl oxygen of anatoxin-a) capable of interacting as a hydrogen bond acceptor with the receptor. A third element of the Beers-Reich pharmacophore (implicit in the way that the first two are defined) was a distance component i.e. the van der Waals (VDW) surface of the hydrogen bond acceptor was required to be $5.9 \AA$ (the BeersReich distance) from the cationic center. The latter was fundamentally important defining as it did the spatial relationship between the two sites of receptor interaction within the ligand.

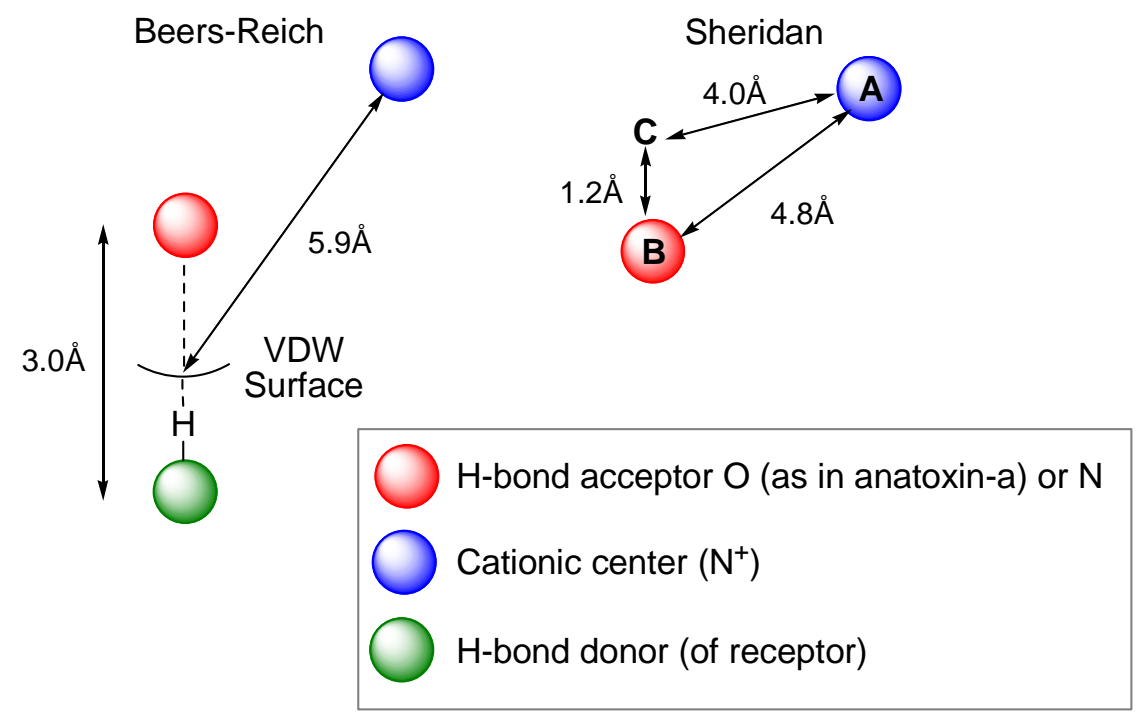

Figure 4. Beers-Reich (1970) and Sheridan (1986) pharmacophores.

Sheridan and co-workers [41] then developed this further and in 1986 proposed a triangular relationship between three pharmacophore components. These were (i) a cationic center (A) (ii) an electronegative element (B) again $\mathrm{O}$ or $\mathrm{N}$, capable of accepting a hydrogen bond and (iii) a "dummy" site or atom (C) along which the hydrogen bond may form. In nicotine, for example, this dummy site (C) was the center of the pyridine ring, while in anatoxin-a $\mathbf{C}$ is the carbon of the carbonyl group. This triangular relationship again served to define the spatial relationship between the critical ligand associated sites, and Sheridan's model required a ligand to meet key distance parameters: A-B $=4.8$ $\pm 0.3 \AA$ Á; A-C = $4.0 \pm 0.3 \AA$ Á; B-C = 1.2 Á. Sheridan also suggested a "Beer-Reich distance” of $5.9 \AA$, 
although given that both groups had used the same molecules and considered the same essential structural features, this level of agreement is not perhaps surprising.

One issue with both of these pharmacophores is that they are inherently "two-dimensional" in nature and do not allow one to predict which of two enantiomers of a putative ligand will be the active enantiomer. This requires another component within the pharmacophore model - to provide "threedimensionality" - and this has been addressed using an element that relates to the lipophilic component of the ligand, such as the bicyclic scaffold associated with anatoxin-a [42].

Given that two key heteroatoms (often both nitrogen, as in epibatidine and nicotine) are involved in both the Beers-Reich and Sheridan pharmacophores, there have been efforts made to provide models based on an optimal distance between the two nitrogen centers (the so-called $\mathrm{N}-\mathrm{N}$ distance) associated with a given ligand; the "idealized" distance has been suggested as $4.8 \pm 0.3 \AA$ based on the BeersReich and Sheridan models, or 5.5 Á[43]. (Note that for anatoxin-a one has to consider the intramolecular $\mathrm{N}-\mathrm{O}$ distance, but the underlying concept is the same).

This is an attractive concept with rigid agonist candidates because of the limited conformational options that are available to molecules like this. However, pitfalls also exist and one must be aware that competing conformations (i.e. those energetically similar to one another) may have quite different $\mathrm{N}-\mathrm{N}$ distance parameters. Epibatidine is a case in point and low energy conformations are available that give N-N distances ranging between $c a .4 .4$ and ca. $5.7 \AA$ [43]. Similarly for anatoxin-a, the s-cis

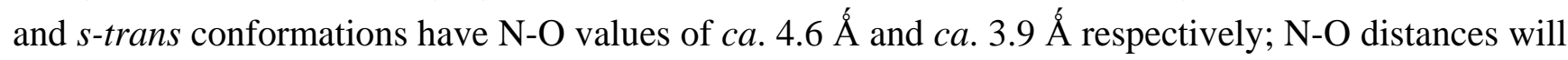
vary given that there are a range of conformational possibilities associated with low energy states. The low value associated with s-trans is interesting given that the s-trans conformer now looks like a reasonable structure for the bioactive conformer of anatoxin-a (see below). Over recent years, no agreement has been reached as to the "optimal" $\mathrm{N}-\mathrm{N}$ (or $\mathrm{N}-\mathrm{O}$ ) distance for viable nicotinic ligands. Values ranging from $4.5 \AA$ to $>6 \AA$ having been proposed, and an analysis of this type, in isolation from other pharmacophore parameters, has to be treated with caution.

Pettersson and co-workers have provided one of the most recent contributions to this area [44-46]. Their model also links N-N distances to activity, however, this is not regarded as either an essential or a unique pharmacophore component. Rather the Novo Nordisk nicotinic pharmacophore maps key interatomic distances and angles as illustrated in Figure 5 for nicotine.

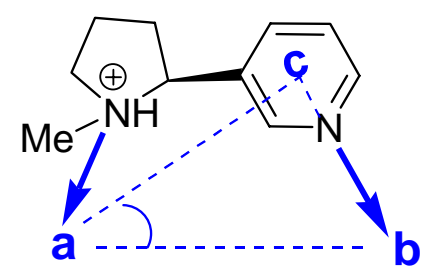

$$
\begin{aligned}
& \mathbf{a}-\mathbf{b}=7.3-8.0 \AA \\
& \mathbf{a - c}=6.5-7.4 \AA \\
& \Delta \mathbf{b a c}=30.4-35.8^{\circ}
\end{aligned}
$$

Figure 5. The Novo Nordisk (1999-2001) nicotinic pharmacophore (as applied to nicotine) [44-46].

This vector-based model was developed and refined using a range of agonists with quite different molecular structures and binding activities, and this model has been used by others, including ourselves, to rationalise activity trends. 
The Novo Nordisk model defines three site points: a relates to the cationic (usually protonated) nitrogen center, $\mathbf{b}$ correlates to the heteroatom ( $\mathrm{N}$ or $\mathrm{O}$ ) that is a hydrogen bond acceptor, and point $\mathbf{c}$ is the centre of a heteroatom ring (as in pyridine) or $\mathrm{C}=\mathrm{O}$ (as in anatoxin-a). Sites a and $\mathbf{b}$ are located at $2.9 \AA$ from the corresponding atoms and in the direction of the lone pair of electrons associated with each atom. The angle ( $\Delta \mathrm{bac}$ ) between the interatomic distance vectors a-b and a-c, and the distance ab and a-c are the key parameters and idealised values are shown in Figure 5. This model indicates that it is not $\mathrm{N}-\mathrm{N}$ (or N-O) distance that is a key determinant for nicotinic activity, rather it is the vectors to points a and $\mathbf{b}$ that are important. In this way, biologically active ligand classes with "short" and "long” N-N or N-O distances can be accommodated by this vector based model.

Finally, it is important to appreciate that the Novo Nordisk model was developed to cater for the $\alpha 4 \beta 2$ neuronal nAChR subtype. This is significant because the need to discriminate between receptor subtypes is crucial for longer term therapeutic applications, and more work to provide specific pharmacophores that highlight the differences associated with subtype-selective binding modes are needed. It is also worth emphasising that binding data alone do not necessarily reflect agonist efficacy, and the ultimate goal for a pharmacophore is to describe ligand-receptor interactions in terms of functional outcomes.

Nicotinic pharmacophores have generated much debate since the early proposals of Beers and Reich, and the situation remains far from clear. We lack models well suited to drug design, an ability to predict agonist, partial agonist and competitive antagonist properties, and current ideas are essentially limited to the $\alpha 4 \beta 2$ neuronal nAChR subtype. The latter is important but by no means the only nAChR to offer therapeutic potential. The reader is referred to recent papers by Glennon $[47,48]$ which review past and current pharmacophore models in the context of their strengths and shortcomings, and Glennon has made the point: "even with 50 years of history, nicotinic pharmacophore models still require extensive work".

\section{Chemistry and Pharmacology of the Homotropane Alkaloids.}

This section has been divided into three parts according to the structural relationship of the homotropane alkaloids to the parent molecule, anatoxin-a. This classification should not be seen as rigid but rather we want to highlight certain key questions and relationships that have been touched on earlier within this chapter. Our aim is to provide an overview of the chemistry that has been employed and we will discuss the pharmacology in terms of the ability of ligands to bind and activate nAChRs.

\section{I. $\quad$ Structural modifications to the periphery of anatoxin-a.}

The bulk of work done to modify anatoxin-a has focussed on the core structure with a number of aims and limitations being simultaneously involved. Clearly, $N(9)$ and the region associated with the carbonyl function (i.e. $C(10)$ and $C(11)$ ) of anatoxin-a are both attractive positions for synthetic manipulations (Figure 6). These represent reactive entities in their own right and these are also the two sites most intimately associated with the nicotinic activity profile of anatoxin-a. Making modifications at these sites is a relatively straightforward task but has the bonus that even relatively small changes may provide valuable information on the mode of binding of the ligand to the nAChR 
[49]. Access to other parts of the anatoxin-a skeleton does depend on the nature of the synthetic strategy employed. The ability to manipulate at $C(3)$ and $C(4)$ is more limited, but possible (see below), but $C(7)$ and $C(8)$ are more difficult regions of the molecule to gain access to.

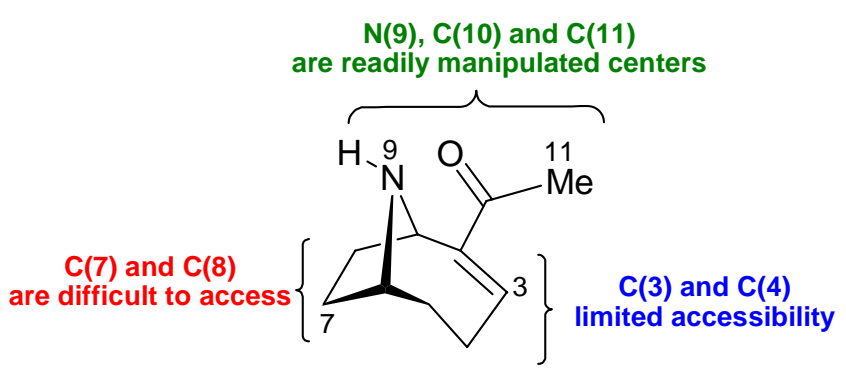

(+)-Anatoxin-a 1

Figure 6. Synthetic accessibility for the modification of anatoxin-a.

Much of the synthetic work reported in this section was carried out by the Rapoport group (see Figure 7), who also developed some of the earliest but also most elegant and efficient synthetic entries to racemic and (+)- and (-)-anatoxin-a [50,51]. Analogues 9 were not prepared at random, but were designed to address issues that contemporary pharmacophore models raised [52, 53].

The ability to $N$-methylate at $N(9)$, or $N, N$-dimethylation (to provide a quaternary ammonium salt) to give 9a and $\mathbf{9 b}$ respectively, offered an opportunity to probe the role and importance of the cationic center [52] (Note that $N$-methyl anatoxin-a 9a was also an intermediate in Edwards' synthesis of anatoxin-a from cocaine) [33]. Rapoport had previously determined the pKa of anatoxin-a as 9.4, which means that at physiological pH (7.2) anatoxin-a exists in $>99 \%$ of the protonated form [32]. $N$ Methylation of anatoxin-a has consistently resulted in diminished nicotinic activity, in activation of muscle nAChR [54,55], in binding to $\alpha 4 \beta 2 *$ and $\alpha 7$ neuronal nAChR [56] (see Figure 8) and with respect to in vivo toxicity [57]. This is an interesting observation as $N$-methylation of other semi-rigid agonists, notably ferruginine and to a lesser extent nicotine, results in enhanced activity [36]. In the case of anatoxin-a, the increased bulk associated with the homotropane skeleton may already place limitations on the ability of the receptor to bind the ligand in a particular (and required) orientation. This limit is then exceeded by $N$-methylation. As a result binding is poor but this remains speculation in the absence of information on the precise mode of binding and the local environment associated with the binding site. 
<smiles>CC(=O)C1=CCC[C@@H]2CC[C@H]1N2C</smiles>

9a<smiles>CC(C)(O)C1=CCC[C@@H]2CC[C@H]1N2</smiles>

9f<smiles>O=CC1=CCC[C@@H]2CC[C@H]1N2</smiles>

$9 m$

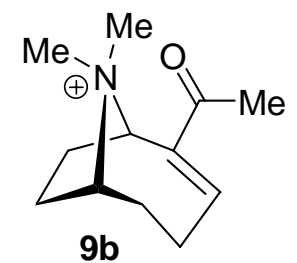

$9 b$

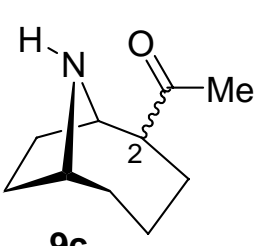

9c<smiles>[R]C1CC[C@@H]2CCC=C([C@H](C)O)[C@@H]1N2[R]</smiles>

9e $\mathrm{R}=\mathrm{Me}$

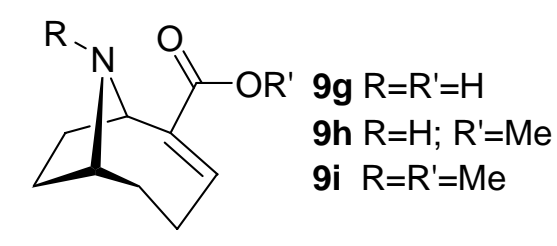<smiles>[Y]C(=O)C1=CCC2CCC1NN2</smiles><smiles>CO[NH2+]C1=CCC[C@@H]2CC[C@H]1N2</smiles>

$9 n$

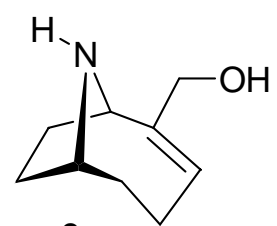

90

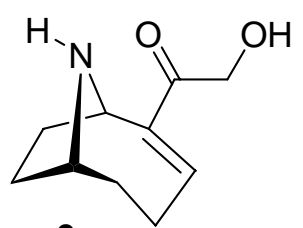

$9 p$<smiles>CC(=O)O[C@@H]1CCC[C@@H]2CC[C@@H]1N2C</smiles>

10<smiles>CC(=O)OCC[N+](C)(C)C</smiles>

Figure 7. Synthetic modifications to anatoxin-a and constrained acetylcholine analogues based on a homotropane scaffold (the acetylcholine substrucutre within ligand 10 is highlighted in red) [50-53].

Synthetic chemistry also allowed the precise spatial distribution of the two pharmacophore components to be explored. This was done by reduction of the $C(2)-C(3)$ double bond to provide two diastereomers (at $C(2)$ ) of dihydroanatoxin-a 9c and reduction of the $C(10)$ carbonyl function provided diastereomeric (10R and 10S) secondary alcohols 9d [52]. Not only do these molecules differ in spatial terms (N-O distance), but there is a difference associated with the ability of oxygen to now act as a hydrogen-bond acceptor. Dihydroanatoxin was one order of magnitude less potent than anatoxin-a in a range of assays, whereas the alcohol analogues 9d were substantially less potent [56,58]. Combining $\mathrm{N}$-methylation and carbonyl group reduction provided a new set of ligands 9e that displayed even greater loss of nicotinic activity (illustrated in Figure 8). 


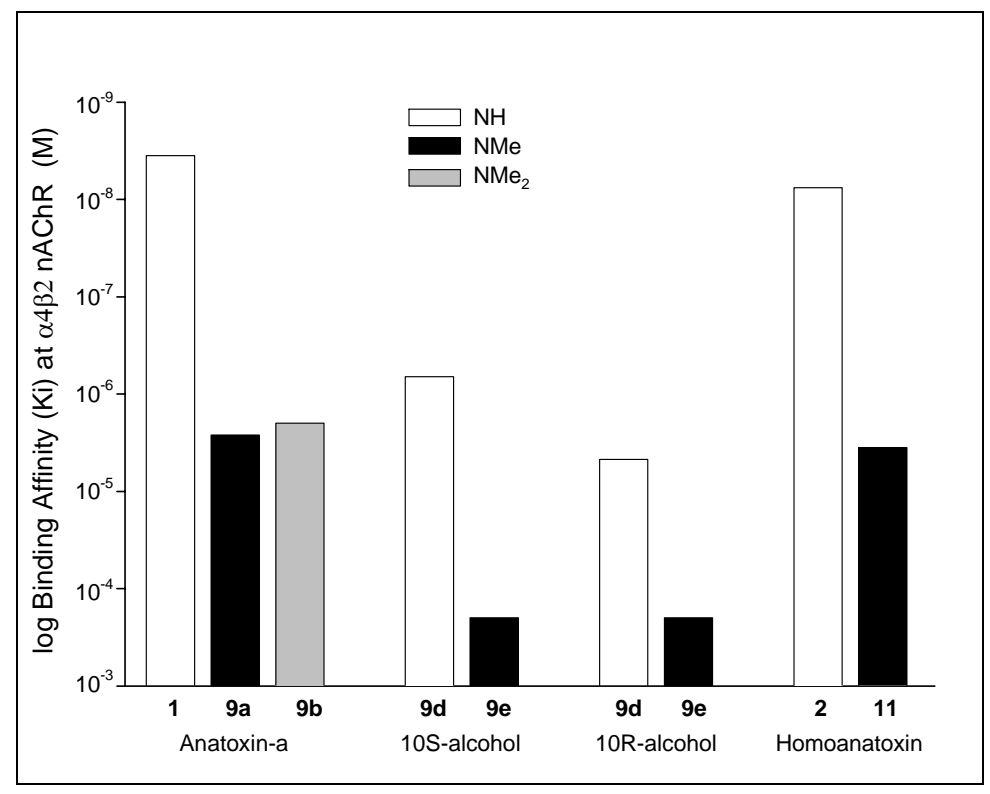

Figure 8. Affinities of anatoxin-a and some derivatives for binding to $\alpha 4 \beta 2 *$ nAChR, and the effect of $N$-methylation. Ki values for inhibition of $\left[{ }^{3} \mathrm{H}\right]$ nicotine binding to rat brain P2 membranes were determined for each ligand. Data from $[19,56]$.

The environment around $C(10)$, the region implicated as a hydrogen bond acceptor, is a key feature of anatoxin-a, and a variety of ligands were prepared in which the steric and electronic properties of this region of the ligand had been altered [53]. The analogues reported included tertiary alcohol 9f, carbonyl modifications to provide carboxylic acid $\mathbf{9 g}$, ester $\mathbf{9 h}$ and $\mathbf{9 i}$, and amide $\mathbf{9 j} \mathbf{j} \mathbf{l}$ variants, as well as aldehyde 9m, oxime 9n, allylic alcohol 9o and the $\alpha$-functionalised ketone 9p. These ligands all had reduced activity, compared with anatoxin-a, but it was noted that $N$-alkoxy amides $9 \mathbf{k}$ and $9 \mathbf{l}$ retained greater affinity at neuronal $\alpha 4 \beta 2 *$ nAChR binding sites labelled with $\left[{ }^{3} \mathrm{H}\right]$ nicotine relative to brain $\alpha 7$ or muscle nAChR [56]. This suggested a basis for subtype selectivity that was encompassed in the isoxazole-containing ABT418 developed by Abbott [59].

Rapoport also recognized a role for the azabicyclic scaffold of anatoxin-a as a means for generating novel conformationally constrained variants of acetylcholine itself [52]. With this objective in mind, the diastereomeric secondary acetates $\mathbf{1 0}$ were prepared, and the relationship between these and acetylcholine is also presented in Figure 7.

Our own groups have investigated modifications at $C(11)$ of anatoxin-a based on the option to generate enol/enolate reactivity at this site. Objectives here were to develop synthetic methodologies to make available a series of anatoxin-a derivatives that would provide ultimately substrates that could be incorporated into polymer bound affinity ligands and radiolabeled variants. One issue was how to incorporate a stable ${ }^{3} \mathrm{H}$ label into anatoxin-a? $N$-Methylation (as in 9a) leads to a significant loss in nicotinic activity and $C$-tritiation (at $C(11)$ ) involves a labile site where proton (tritium) exchange (via enolization) occurs readily; this was easily demonstrated with the ${ }^{2} \mathrm{H}$ analogue. Extending the side chain by one methylene unit offered a solution to this problem, and enolization and methylation of $N$ Boc-protected anatoxin-a, followed by $N$-deprotection, provided homoanatoxin-a 2 (Figure 9) [19]. In contrast to the analogues discussed above, homoanatoxin retained potency similar to that of anatoxin-a, with Ki values of $7.5 \mathrm{nM}$ and $1.1 \mu \mathrm{M}$ in competition binding assays for neuronal $\alpha 4 \beta 2$ and $\alpha 7 \mathrm{nAChR}$ 
binding sites, respectively. Furthermore, homoanatoxin showed little inhibition of muscarinic binding defined by $\left[{ }^{3} \mathrm{H}\right]$-quinuclidinylbenzilate. Homoanatoxin is a potent nicotinic agonist in frog muscle contracture assays, having four times the potency of carbamylcholine and one tenth of the activity of anatoxin-a. The $N$-methyl variant $\mathbf{1 1}$ of homoanatoxin was also synthesized and evaluated. It was more than two orders of magnitude weaker than 2 in both functional and binding assays [19], consistent with the trend displayed by anatoxin-a (Figure 8).

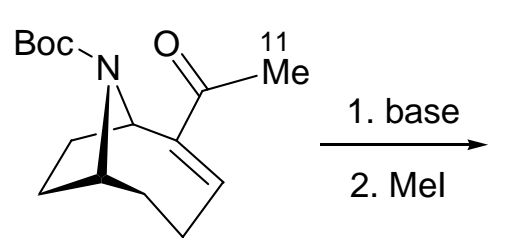

N-Boc anatoxin-a

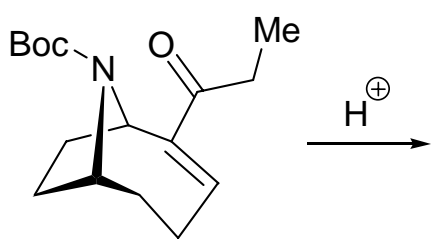

Homoanatoxin 2

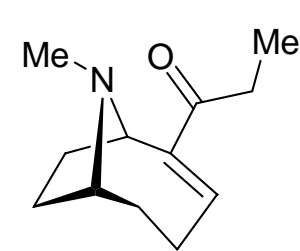

11

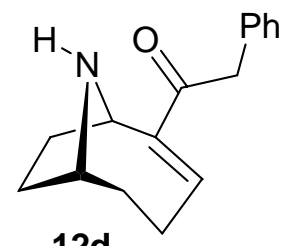

12d

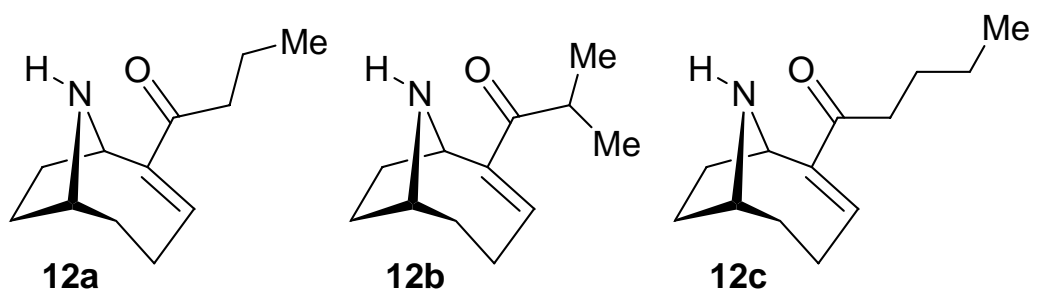

$12 b$

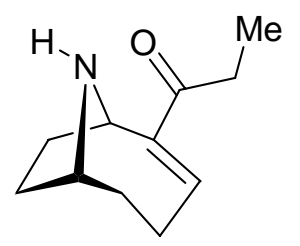

12c

Figure 9. Synthetic modifications associated with $C(11)$ of anatoxin-a. Synthesis of homoanatoxin and related analogues.

This enolate chemistry was extended to include more sterically demanding side chains (the propyl and isopropyl variants 12a, 12b and 12c) to probe to tolerance of the receptor to steric bulk in this region [60]. More recently, and using quite different chemistry, Parsons provided 12d, the first example of an $\alpha$-arylated anatoxin-a derivative [61]. An amide-based model affinity ligand $\mathbf{1 3}$ was also prepared using enolate-based chemistry demonstrating that this strategy is applicable to more demanding substrates [62].

Alternative methods for functionalisation of $C(11)$ have been developed (Figure 10). Again, it is important to appreciate that an ability to manipulate a molecule in as many ways as possible reduces the reliance on a particular methodology and opens the ways for a wider range of variants to be made available. Anatoxin-a is a synthetically demanding substrate and a number of methods for oxidation of $C(11)$ failed. Koser's reagent $(\mathrm{PhI}(\mathrm{OH}) \mathrm{OTs})$ was successful and this provided a good and flexible level of electrophilic reactivity at $C(11)$ which was exploited with sulfur nucleophiles to provide $S$ linked $C(11)$ derivatives $\mathbf{1 4 a} \mathbf{a} \mathbf{b}$, and two dansylated analogues $\mathbf{1 5} \mathbf{a} / \mathbf{b}$ of anatoxin-a [63]. While the 
thiomethyl derivative 14a retained activity at neuronal $\mathrm{nAChR}$ binding sites, incorporation of the dansyl moiety (as in 15a/b) resulted in substantial decreases in binding affinity. An issue here was the reduced solubility associated with $\mathbf{1 5}$ which may have been a contributing factor to the low potency observed.

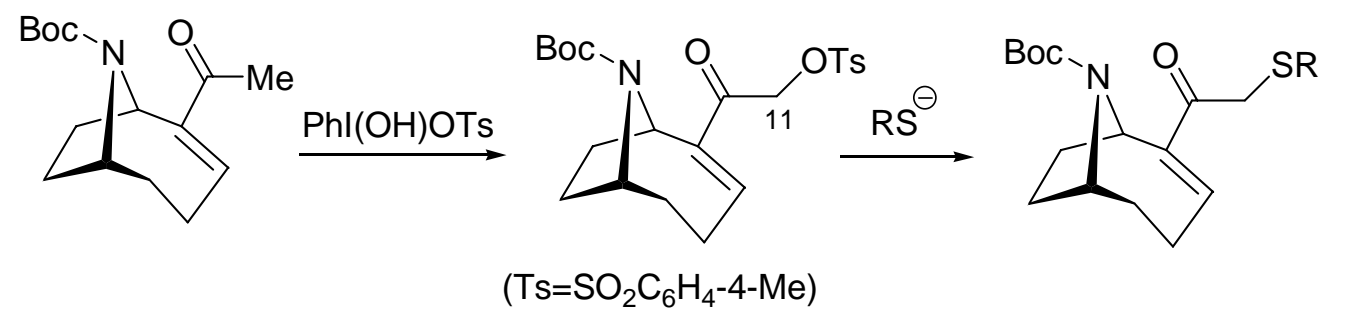

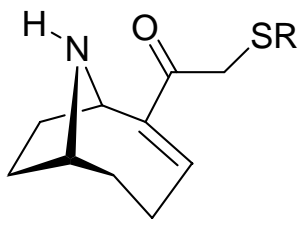

14a $\mathrm{R}=\mathrm{Me}$ 14b $\mathrm{R}=\mathrm{Ph}$

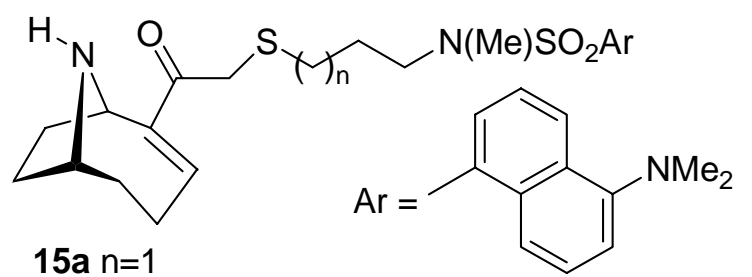

$15 b \mathrm{~b}=7$

Figure 10. Synthetic modifications associated with oxidation and substitution at $C(11)$ of anatoxin-a.

\section{S-Cis vs. S-Trans. What is the bioactive conformation of anatoxin-a?}

As alluded to earlier, anatoxin-a is an attractive candidate for pharmacophore development because it combines a good nicotinic agonist profile with limited and localised conformational mobility. The mobility of anatoxin-a is primarily associated with rotation about the $C(2)-C(10)$ leading to two low energy categories of conformation: s-cis and s-trans (see Figure 3). It should be noted that there are a number of energetically similar conformations associated with each of the s-cis and s-trans arrangements depending on the precise orientation of the enone portion with respect to the azabicycle moiety, and changes within the azabicycle itself. However; these need only be considered as comparatively minor structural perturbations. The relationship between the s-cis and s-trans of anatoxin-a and existing pharmacophores does however raise a question: could a knowledge of the bioactive conformation ( $s$-cis or s-trans) of anatoxin-a make a significant contribution to the refinement of the nicotinic pharmacophore? Clearly the answer to this is yes, but simple examination of the structural parameters (N-O distances etc.) associated with these two primary conformational options does not provide any clear guidance. Accordingly, a number of groups have recognized the need to investigate conformationally constrained anatoxin-a variants in order to shed light on the relative biological importance of s-cis and s-trans anatoxin-a .

Activity in this area was initiated by conclusions drawn in 1983 on the preferred conformation of anatoxin-a. Koskinen and Rapoport [32] had reported the solid state structure of anatoxin-a (which showed the s-trans arrangement), together with its solution conformation as determined by ${ }^{1} \mathrm{H}$ NMR data. They demonstrated that the enone unit showed rotational mobility, as expected, but these authors 
went on to suggest that the s-cis conformer was the bioactive form. This conclusion was based on molecular mechanics calculations using the free base i.e. unprotonated form of anatoxin-a to assess the relative energetics of the two (s-cis vs. s-trans) conformational possibilities. However, the energy difference $\left(3.4 \mathrm{~kJ} \mathrm{~mol}^{-1}\right)$ between these two conformations corresponds to a minor preference for the $s$ cis form that at room temperature is not a significant energy hurdle to overcome. Later calculations using the protonated and, given the $\mathrm{pk}_{\mathrm{A}}$ of anatoxin-a, the biologically more relevant form of anatoxina concluded that not only was the energy difference between s-cis and s-trans larger $\left(9.4 \mathrm{~kJ} \mathrm{~mol}^{-1}\right)$ but that it also favoured the s-trans conformer i.e. s-trans was more stable [64]. The message to take from this is that no truly definitive conclusions can be drawn from either set of calculations. The energy differences (9.4 or $3.4 \mathrm{~kJ} \mathrm{~mol}^{-1}$ ) are not overriding in terms of accessibility to the higher energy conformational state and, of course, take no account of the energetics of binding and the impact that this would have on conformational populations. An alternative computational approach to deducing the relative significance of s-cis vs. s-trans anatoxin-a was undertaken by Hacksell based on "excluded receptor volumes" and this study also favoured s-trans anatoxin-a as the bioactive conformer [65].

Kanne and Abood provided the first conformationally constrained variant of anatoxin-a, when they reported the synthesis of the two closely related pyrido[3, 4-b]homotropanes 16a (PHT) and 16b (2'methyl-PHT); these molecules can also be regarded as constrained variants of nicotine (Figure 11) [66,67]. The unsubstituted derivative 16a was a potent nicotinic agonist, which lends support to the suggestion of Koskenin and Rapoport that the bioactive conformer of anatoxin-a is the s-cis form. However, and surprisingly, the methyl variant $\mathbf{1 6 b}$, which is arguably more closely related to anatoxina, showed a significant decrease in nicotinic binding affinity. The reasons behind these differences in potency are still unclear.

More recently, Seitz and co-workers reported the synthesis of the pyridazine analogue $\mathbf{1 7}$ of PHT [68]. Pyridazine 17 interacted with $\alpha 4 \beta 2 \mathrm{nAChR}$ binding sites with $\mathrm{K}_{\mathrm{i}}=35 \mathrm{nM}$, which suggests that it is a weaker ligand than anatoxin-a $\left(\mathrm{K}_{\mathrm{i}}=1.1 \mathrm{nM}\right)$ and PHT 16a $\left(\mathrm{IC}_{50}=5 \mathrm{nM}\right)$. This may be explained by the reduced basicity (and hence hydrogen bond acceptor capacity) associated with a pyridazine vs. a pyridine (as in 16a).

An alternative s-cis variant of anatoxin-a was designed within our groups in order to provide a mechanism for conformational constraint with a minimal structural disturbance [69]. Hydroxyanatoxin-a 18 uses the keto-enol tautomer of a 1,3-diketone (and the associated intramolecular hydrogen bond) as a conformational lock, and this system was shown (by X-ray crystallography and NMR) to exist as a "symmetrical" enol form i.e. there was not obvious preference for one keto-enol tautomer over the other. However, hydroxyanatoxin-a did not display nicotinic activity in binding assays and neither did the corresponding pyrazole 19 which was readily prepared from 18 and represents an alternative conformationally constrained s-cis variant. 


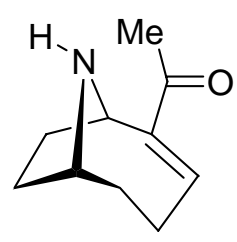

S-cis conformer of anatoxin-a

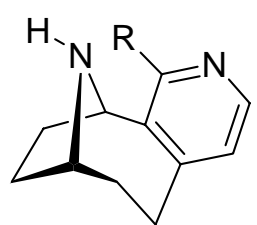

$16 a \mathrm{R}=\mathrm{H}(\mathrm{PHT})$

16b $\mathrm{R}=\mathrm{Me}$

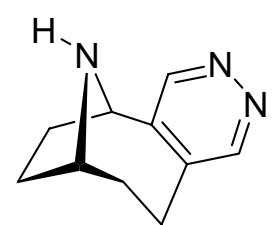

17

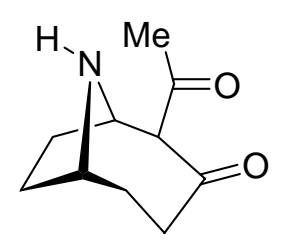

1,3-diketone form

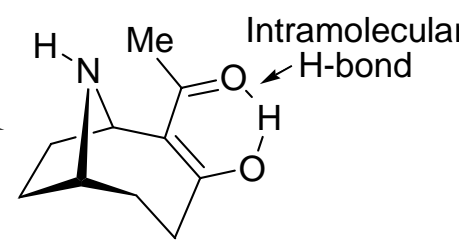

18

keto-enol

form

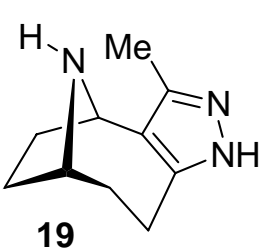

19

Figure 11. Mimics of the s-cis conformer of anatoxin-a.

Significant levels of nicotinic activity have, however, been reported in the literature for two mimics of the $s$-trans conformation of anatoxin-a (Figure 12). Rapoport reported the synthesis of analogue $\mathbf{2 0}$, together with two other isomeric structures 21 and 22 (note that for 22 the stereochemistry at $\mathrm{C}(2)$ could not be assigned) [70]. However, biological data for $\mathbf{2 0}$ were not available until this analogue was re-evaluated by the Abbott group [71]. Analogue 20 showed $K_{i}(\alpha 4 \beta 2 \mathrm{nAChR}$, rat brain) $4.6 \mathrm{nM}$ which is approximately ten fold less active than anatoxin-a. No data are available for either of the isomeric structures $\mathbf{2 1}$ or $\mathbf{2 2 .}$

Intriguingly, the other s-trans variant of anatoxin-a to have been examined is pinnamine 3 (Figure 1). This molecule is highly reminiscent of the isomeric structure 22 reported by Rapoport, and also contains the $C(2)$ (pinnamine numbering) ethyl group, which further correlates pinnamine to propylanatoxin 12a. For this reason, pinnamine not only appears to be an s-trans mimic but also good "next generation anatoxin-a" natural product lead structure from which to develop new nicotinic agonists.

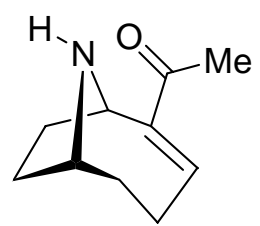

S-trans conformer of anatoxin-a

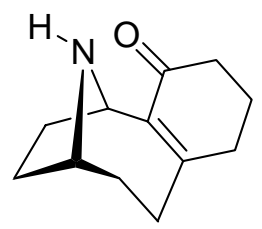

20

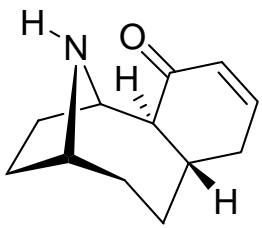

21

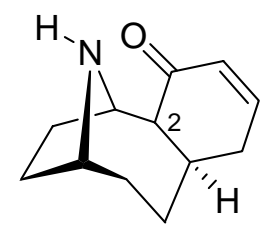

22

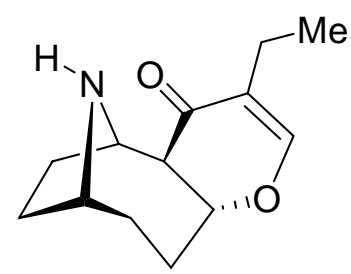

(+)-Pinnamine 3

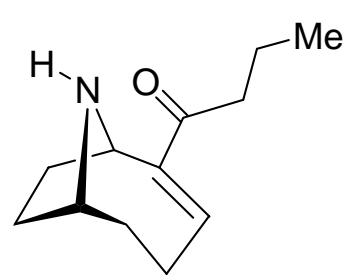

$12 a$

Figure 12. Mimics of the s-trans conformer of anatoxin-a. 
In summary, based on the work that has been described to date in the literature, the conclusion that the s-trans form of anatoxin-a (and the analogous conformations of related structures - see below) is the bioactive conformation is not unreasonable. This statement is, however, made in the absence of any data being available for a direct observation of the ligand-receptor complex. With the advent of the crystal structure of the acetylcholine binding protein from Lymnaea (see [7]), and homology modelling of nAChR binding sites, docking studies with other agonists have been performed [72]. This approach could be extended to anatoxin-a and its family of ligands to provide data to complement the traditional SAR approach and serve to progress the s-cis vs s-trans debate.

\section{Anatoxin-a Hybrids: UB-165.}

We have already discussed the anatoxin-a/nicotine hybrid (PHT, 16a) reported by Kanne, and given the diversity of nicotinic ligands currently available [14], the possibility of "mixing and matching" features associated with different agonists to generate new lead structures is a powerful design concept. Our attention focussed on epibatidine which is not only a very potent nicotinic agonist but also a ligand that shows negligible enantiospecificity i.e. both enantiomers of epibatidine are essentially equipotent [37], in contrast to the enantiomeric specificity associated with anatoxin-a. This raised the question as to which component (azabicycle vs. pyridine of anatoxin-a and epibatidine respectively) contributed to this enantiomeric discrimination.

We addressed this issue by designing UB-165 23 that combines the larger azabicycle (homotropane fragment) of anatoxin-a with the 2-chloropyridine present in epibatidine; this was the first example of an anatoxin-a/epibatidine hybrid [73]. Both enantiomers of UB-165 were prepared and only one (the enantiomer that corresponded to (+)-anatoxin-a) showed agonist activity. The other enantiomer (entUB-165, Figure 13) was inactive. Furthermore, in contrast to all of the variants of anatoxin-a described above, UB-165 showed enhanced potency that was intermediate between that of the two parent compounds - anatoxin-a and epibatidine. Thus although UB-165 is not a naturally occurring toxin, its pharmacology represents a significant development and advance in the field. In addition to its nicotinic potency and enantiospecificity, UB-165 has the unexpected property of being a partial agonist at $\alpha 4 \beta 2 *$ nAChR. That is to say, it activates this nAChR subtype with low efficacy, resulting in a smaller response than achieved with acetylcholine, nicotine, epibatidine or anatoxin-a [74,75]. This property was exploited to provide pharmacological evidence for the involvement of $\alpha 4 \beta 2 *$ nAChR in the presynaptic modulation of dopamine release from striatal nerve terminals [74]. Partial agonism presents another challenge for the nicotinic pharmacophore, that ultimately should be able to account for the reduced efficiency of coupling between binding and channel opening shown by certain agonists, including UB-165 and cytisine.

UB-165 has provided a valuable opportunity to develop another series of novel ligands, carried out independently by two groups, resulting in further advances in probing nAChR structure-activity relationships. The basic strategy used to synthesise UB-165 is outlined in Figure 13, and relies on a palladium-mediated cross coupling step to connect the azabicycle and heteroaryl moieties. This approach, the versatility of which is linked to its high convergency, has been applied to generate a variety of novel heterocyclic analogues by both our groups and the group of Seitz. The first generation of UB-165 analogues focussed on modifying the heteroaryl moiety, and the synthesis and 
pharmacology of the 2- and 4-pyrido isomers 24 and 25, together with deschloro UB-165 26 were reported; the chloro substitutent is not crucial for nicotinic activity [76].

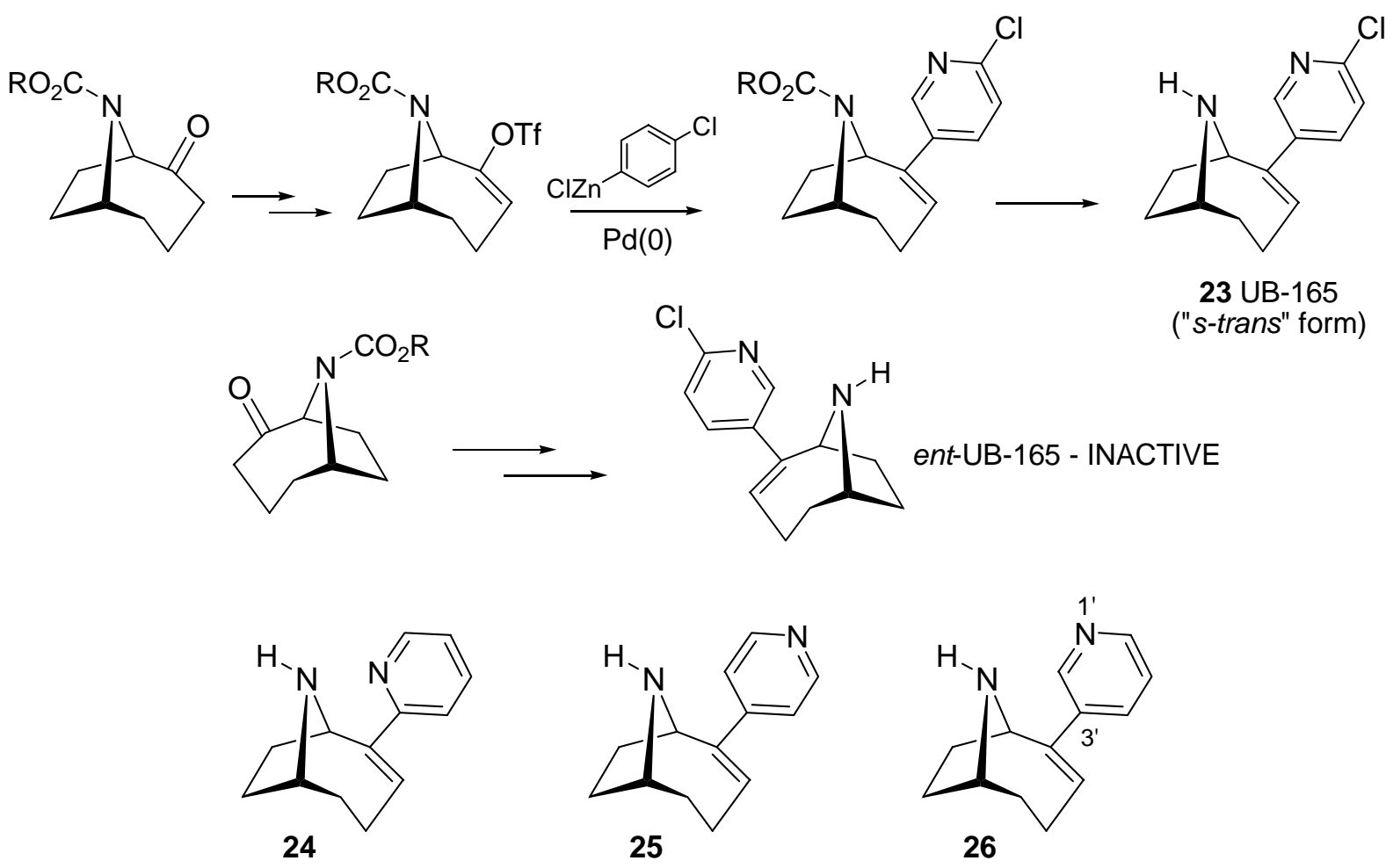

Figure 13. Synthesis of UB-165 and “first generation” azine-based analogues. Ligands 23 and 26 are drawn in their "s-trans" conformations.

Azine analogues 24-26 are of significance because they span a large range of N-N distances, and these molecules have been related to the distance-based Novo Nordisk pharmacophore [76] (Figure 5). For the unsymmetrical substrates $\mathbf{2 4}$ and $\mathbf{2 6}$ (the 4'-pyridyl derivative $\mathbf{2 5}$ is regarded as "symmetrical" for the purposes of this discussion), there are s-cis and s-trans conformations accessible that are analogous to those discussed above for anatoxin-a. (In 23 and 26, $N\left(1^{\prime}\right)$ is regarded as equivalent to the $\mathrm{O}$ of anatoxin-a, so for this reason only we refer to $\mathbf{2 3}$ and $\mathbf{2 6}$ as drawn in Figure 13 as the s-trans conformers). In terms of the pharmacological profiles observed, then the 3'-substituted pyridyl moiety (as in 23 and 26) was crucial for nicotinic potency, and the 2- and 4-pyridine analogues 24 and 25 had much weaker nicotinic activity [76]. When studied against the Novo Nordisk pharmacophore, the "best fit" for $\mathbf{2 3}$ was found for the s-trans conformer (as shown in Figure 13) although a binding mode via the s-cis arrangement could not be ruled out. Interestingly, the 2'-pyridyl variant $\mathbf{2 4}$, which was a weak nicotinic ligand, also achieved conformations that accorded with the Novo Nordisk model. These conformations were, however, higher in energy (4.6 kJ mol${ }^{-1}$ above the global minimum) and, while not inaccessible, may be expected to be poorly populated.

Diazine variants 27-30 of UB-165 23 have also been reported, again using a Pd(0)- cross coupling as the pivotal synthetic transformation (Figure 14) [76,77]. These represent a "second generation" series of ligands and the modifications made here involve introduction of a second nitrogen atom at all 
possible positions within the heteroaryl unit. This serves to moderate both the properties of $N\left(1^{\prime}\right)$ which is the putative hydrogen bond acceptor, and the $\pi$-system associated with the heteroarene. Basicity of the putative hydrogen bond acceptor $\left(N\left(1^{\prime}\right)\right)$ is reduced depending on the position of the second nitrogen atom, and altering $\pi$-electron density offers an opportunity to probe the importance of any $\pi-\pi$ interactions that may be associated with the binding site.

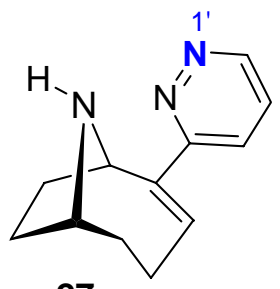

27

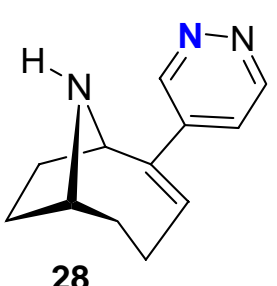

28

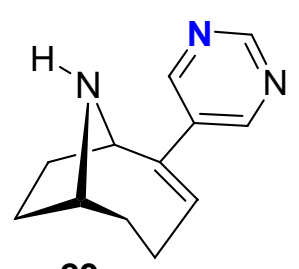

29

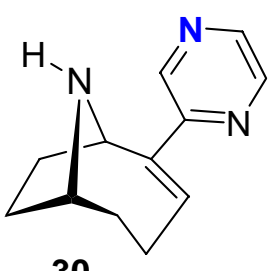

30

Figure 14. "Second generation" diazine-based analogues of UB-165. Putative hydrogen bond acceptor nitrogen atom is highlighted in blue.

Diazines 27-30 do meet the requirements of Novo Nordisk pharmacophore but that is expected given that the "3-pyridyl” moiety has been retained within these ligand structures. Both groups that synthesised some of these diazine variants examined them for binding to $\alpha 4 \beta 2, \alpha 7$ and $\alpha 3 \beta 4 \mathrm{nAChR}$, and observed a similar rank order of potency, with $\mathbf{2 7} \sim \mathbf{2 9}>\mathbf{3 0}>\mathbf{2 8}$, for all three nAChR subtypes. Seitz also evaluated the electron density (basicity) associated with the diazine analogues 28-30 which relates directly to an ability to act as a hydrogen bond acceptor [77]. These calculations show that pyrimidine 29 retains the highest level of electron density on nitrogen. Accordingly, pyrimidine $\mathbf{2 9}$ is predicted to be the most effective as a hydrogen bond acceptor, which in turn correlates to the observed trends in nicotinic potency in binding assays [76,77]. Diazines 27, 29, 30 were also assessed as agonists for activation of $\alpha 3 \beta 4 \mathrm{nAChR}$ [76]. Pyridazine 27 and pyrimidine 29 were equipotent agonists at this nAChR subtype $\left(\mathrm{EC}_{50}=4 \mu \mathrm{M}\right)$ whereas 30 was two orders of magnitude weaker $\left(\mathrm{EC}_{50}>100 \mu \mathrm{M}\right)$, showing good correspondence with the binding data.

A third generation of UB-165 analogues was reported in 2003 and these were based on retaining core 3'-substituted pyridyl unit but allowing additional (phenyl) substitution on the heteroaryl component [78]. Locating an additional phenyl residue at all four possible positions was only possible because of the flexibility associated with the synthetic chemistry that had been developed in the course of developing methodology for UB-165. Four isomeric phenyl-substituted pyridines 31-34 were synthesised and evaluated as nicotinic ligands (Figure 15).

Four significant observations can be made regarding ligands 31-34. Firstly, incorporation of a phenyl substituent at the 2'-position (as in 31) resulted in a complete loss of nicotinic potency against all three receptors subtypes examined ( $\alpha 4 \beta 2, \alpha 7$ and $\alpha 3 \beta 4)$. Secondly, steric bulk associated with a phenyl substituent generally reduces potency compared with deschloro UB-165, but clearly also makes an impact on subtype selectivity. Thirdly, phenyl substitution at the 5'- and 6'-positions (33 and 34 respectively) results in profiles that are qualitatively similar to deschloro UB-165 26: potency at $\alpha 4 \beta 2$ 
$>\alpha 3 \beta 4>>\alpha 7$. However, it should be pointed out that $\mathbf{3 3}$ in particular is less capable than deschloro UB-165 of discriminating between these three receptor subtypes.

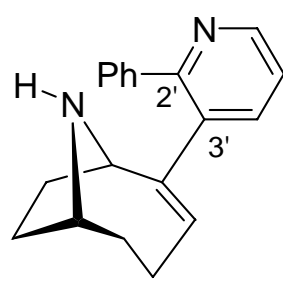

31

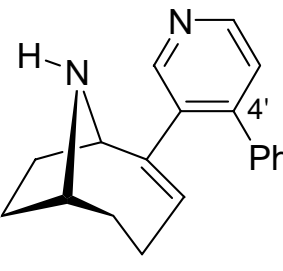

32

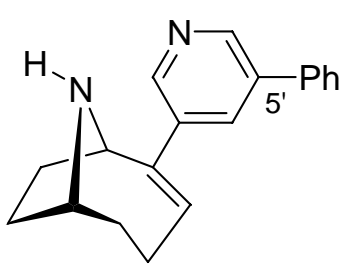

33

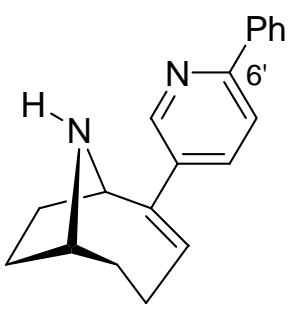

34

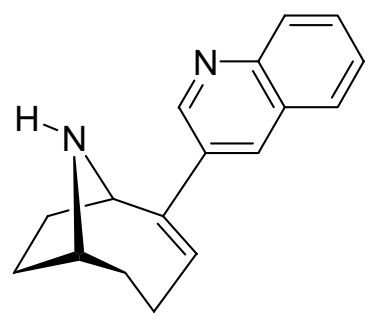

35

Figure 15. “Third generation” pyridyl analogues of UB-165.

The final and perhaps most interesting observation relates to the 4'-phenyl analogue 32. This ligand, while substantially (2 orders of magnitude) less potent than UB-165 23 and deschloro UB-165 26 at $\alpha 4 \beta 2$ and $\alpha 3 \beta 4$ subtypes, retains a comparatively high potency at the $\alpha 7$ receptor. Analogue 32 is only 8.5 times more potent at $\alpha 4 \beta 2$ than at $\alpha 3 \beta 4$ whereas deschloro UB-165 is 52 times more potent, respectively. However, at $\alpha 732$ is only 4 times less potent than at $\alpha 4 \beta 2$, whereas deschloro UB-165 is 200 times less potent at $\alpha 7$. Interestingly, UB-165 shows a binding differential $>10^{4}$ times between these two receptor subtypes.

It is important to appreciate that the positioning of the phenyl substituent on the pyridyl ring can make an impact on conformational preference of the ligand. In the case of 31, $C\left(2^{\prime}\right)$ substitution places the phenyl residue close to $N(9)$ and this may then influence the ability of this center (in its protonated form) to interact with the receptor. Phenyl substitution at $C\left(5^{\prime}\right)$ and $C\left(6^{\prime}\right)$ does not perturb the preferred conformations of ligands 33 and 34, but the phenyl residue does, of course, occupy space. The regions so occupied do not constitute pharmacophore components that make primary interactions with the receptor but nevertheless may influence the binding mode and subsequent activity of the ligand due to spatial constraints. In light of this, we also synthesised the quinoline derivative $\mathbf{3 5}$. This molecule has a relationship to both $\mathbf{3 3}$ and $\mathbf{3 4}$ with an extended $\pi$-system, but the twisted orientation of the biaryl residues associated with $\mathbf{3 3}$ and $\mathbf{3 4}$ (vs. the planer nature of the quinoline unit of 35) would place the biaryl $\pi$-systems in a quite different orientation as compared to 35 . In the event, quinoline 35 showed significantly lower binding affinity values (nM) of 140, 2535 and >50000 for $\alpha 4 \beta 2$, $\alpha 3 \beta 4$ and $\alpha 7$ respectively. 
In the case of the $C\left(4^{\prime}\right)$ variant 32 , this molecule can readily meet the requirements of the Nova Nordisk pharmacophore but selective retention of good binding affinity at $\alpha 7 \mathrm{nAChR}$ may indicate that the phenyl residue occupies a region of space that could usefully be exploited for enhanced $\alpha 7$ nAChR subtype selectivity.

The most recent UB-165 variants to have been reported are the fluoro substituted analogues $\mathbf{3 6}$ and 37 (Figure 16) [79]. The C(6') isomer 36 (the fluoro analogue of UB-165) retained high activity showing binding affinity values (nM) of 0.82 and 0.30 for $\alpha 4 \beta 2$ and $\alpha 7$ respectively. Against these two receptors subtypes, the corresponding C(2') isomer 37 had Ki values of $306 \mathrm{nM}$ and $21 \mathrm{nM}$ respectively high activity. The presence of fluorine would significantly reduce the basicity of the pyridine nitrogen - a key component in terms of the receptor interaction - but this would be expected to be independent of the position of fluorination. Given the relatively undemanding steric nature of fluorine, the biological difference associated with regioisomers $\mathbf{3 6}$ and $\mathbf{3 7}$ is difficult to account at this time.

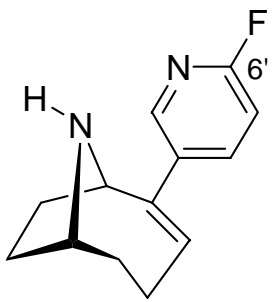

36

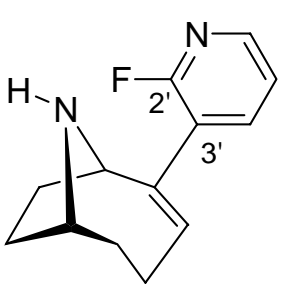

37

Figure 16. C(2) an C(6) Regioisomeric Fluoro Analogues of UB-165.

These types of analogue have a valuable role to play in refining the pharmacophore, and the structural and electronic data associated with the ligands shown in Figures 14, 15 and 16 will enable current models to evolve and strengthen.

\section{Conclusions}

Anatoxin-a represents an important nicotinic agonist that has played a central role in developing our knowledge and understanding of nAChR, by virtue of its potency, nicotinic specificity and similarity to acetylcholine in its agonist actions. Further, extensive interest from the synthetic chemistry community has not only provided us with efficient routes to anatoxin-a itself but also the generation of a wide range of new pharmacological probes, through the ability to manipulate the parent structure. These novel structures have enabled structure-activity relationships to be developed, and helped to focus attention on the significance of reliable nicotinic pharmacophores. Good predictive pharmacophores remain some way off, but this process of evolution and refinement has maintained momentum, and progress in this area is being made.

The structural relationships between different classes of agonist are important, as illustrated by UB165 that has provided further insights into enantiospecificity of nicotinic ligands. In addition, its unexpected partial agonist properties at $\alpha 4 \beta 2 \mathrm{nAChR}$ could be exploited for exploring the functional contribution of this subtype in the brain. Such hybrids open new doors and opportunities: the challenge 
for the chemist is two fold. Firstly, while it is comparatively easy to generate new variants of known ligands, it is critically important to collate the structure-activity relationship information that these generate into a rational and coherent pharmacophore model, ideally one that discriminates between different nAChR subtypes. The second challenge is associated with finding radically different molecular scaffolds that are able to carry the pharmacophore components in order to yield new, viable (and patentable) nicotinic ligands for therapeutic application in an increasing range of clinical targets. Anatoxin-a and its analogues continue to make significant contributions to this quest.

\section{References}

1. Francis, G. Poisonous Australian Lake. Nature 1878, 11-12.

2. James, K. J.; Crowley, J.; Hamilton, B.; Lehane, M.; Skulberg, O.; Furey, A. Anatoxins and degradation products, determined using hybrid quadrupole time-of-flight and quadrupole ion-trap mass spectrometry: forensic investigations of cyanobacterial neurotoxin poisoning. Rapid Commun. Mass Spectrom. 2005, 19, 1167-1175.

3. James, K. J.; Furey, A.; Sherlock, I. R.; Stack, M. A.; Twohig, M.; Caudwell, F. B.; Skulberg, O. M. Sensitive determination of anatoxin-a, homoanatoxin-a and their degradation products by liquid chromatography with fluorimetric detection. J. Chromatogr. A 1998, 798, 147-157.

4. Drager, B. Analysis of tropane and related alkaloids. J. Chromatogr. A 2002, 978, 1-35.

5. Pravda, M.; Kreuzer, M. P.; Guilbault, G. G. Analysis of important freshwater and marine toxins. Anal. Lett. 2002, 35, 1-15.

6. Mansell, H. L. Synthetic approaches to anatoxin-a. Tetrahedron 1996, 52, 6025-6061.

7. Karlin, A. Emerging structure of the nicotinic acetylcholine receptors. Nat. Rev. Neurosci. 2002, 3, 102-114.

8. Spivak, C. E.; Witkop, B.; Albuquerque, E. X. Anatoxin-a: a novel, potent agonist at the nicotinic receptor. Mol. Pharmacol. 1980, 18, 384-394.

9. Carmichael, W. W.; Biggs, D. F.; Gorham, P. R. Toxicology and Pharmacological Action of Anabaena Flos-Aquae Toxin. Science 1975, 187, 542-544.

10. Rowell, R. R.; Wonnacott, S. Evidence for functional activity of up-regulated nicotine binding sites in rat striatal synaptosomes. J. Neurochem. 1990, 55, 2105-2110.

11. Stolerman, I. P.; Albuquerque, E. X.; Garcha, H. S. Behavioural effects of anatoxin, a potent nicotinic agonist, in rats. Neuropharmacology 1992, 31, 311-314.

12. Lukas, R. J.; Changeux, J.-P.; le_Novere, N.; Albuquerque, E. X.; Balfour, D. J. K.; Berg, D. K.; Bertrand, D.; Chiappinelli, V. A.; Clarke, P. B. S.; Collins, A. C.; Dani, J. A.; Grady, S. A.; Kellar, K. J.; Lindstrom, J. M.; Marks, M. J.; Quik, M.; Taylor, P. W.; Wonnacott, S. International Union of Pharmacology. XX. Current status of the nomenclature for nicotinic acetylcholine receptors and their subunits. Pharmacol. Rev. 1999, 51, 397-401.

13. Thomas, P.; Stephens, M.; Wilkie, G.; Amar, M.; Lunt, G. G.; Whiting, P.; Gallagher, T.; Pereira, E.; Alkondon, M.; Albuquerque, E. X.; Wonnacott, S. (+)-Anatoxin-a is a potent agonist at neuronal nicotinic acetylcholine receptors. J. Neurochem. 1993, 60, 2308-2311. 
14. Jensen, A. A.; Frolund, B.; Liljefors, T.; Krogsgaard-Larsen, P. Neuronal nicotinic acetylcholine receptors: structural revelations, target identifications, and therapeutic inspirations. J. Med. Chem. 2005, 48, 4705-4745.

15. MacAllan, D. R. E., Lunt, G. G., Wonnacott, S., Aracava, Y., Albuquerque, E. X. Methyllycaconitine and anatoxin-a differentiate between nicotinic receptors in vertebrate and invertebrate CNS. FEBS Lett. 1988, 226, 357-363.

16. Dajas-Bailador, F.; Wonnacott, S. Nicotinic acetylcholine receptors and the regulation of neuronal signalling. Trends Pharmacol. Sci. 2004, 25, 317-324.

17. Cassels, B. K.; Bermudez, I.; Dajas, F.; Abin-Carriquiry, J. A.; Wonnacott, S. From ligand design to therapeutic efficacy: the challenge for nicotinic receptor research. Drug Discovery Today 2005, 10, 1657-1665.

18. Devlin, J. P.; Edwards, O. E.; Gorham, P. R.; Hunter, N. R.; Pike, R. K.; Stavric, B. Anatoxin-a, a Toxic Alkaloid from Anabaena-Flos-Aquae Nrc-44h. Can. J. Chem. 1977, 55, 1367-1371.

19. Wonnacott, S.; Swanson, K. L.; Albuquerque, E. X.; Huby, N. J. S.; Thompson, P.; Gallagher, T. Homoanatoxin - a Potent Analog of Anatoxin-a. Biochem. Pharmacol. 1992, 43, 419-423.

20. Skulberg, O. M.; Carmichael, W. W.; Andersen, R. A.; Matsunaga, S.; Moore, R. E.; Skulberg, R. Investigations of a Neurotoxic Oscillatorialean Strain (Cyanophyceae) and Its Toxin - Isolation and Characterization of Homoanatoxin-A. Environ. Toxicol. Chem. 1992, 11, 321-329.

21. Zotou, A.; Jefferies, T. M.; Brough, P. A.; Gallagher, T. Determination of Anatoxin-a and Homoanatoxin in Blue-Green-Algal Extracts by High-Performance Liquid-Chromatography and Gas-Chromatography Mass-Spectrometry. Analyst 1993, 118, 753-758.

22. Takada, N.; Iwatsuki, M.; Suenaga, K.; Uemura, D. Pinnamine, an alkaloidal marine toxin, isolated from Pinna muricata. Tetrahedron Lett. 2000, 41, 6425-6428.

23. Kigoshi, H.; Hayashi, N.; Uemura, D. Stereoselective synthesis of pinnamine, an alkaloidal marine toxin from Pinna muricata. Tetrahedron Lett. 2001, 42, 7469-7471.

24. Hjelmgaard, T.; Sotofte, I.; Tanner, D. Total synthesis of pinnamine and anatoxin-a via a common intermediate. A caveat on the anatoxin-a endgame. J. Org. Chem. 2005, 70, 5688-5697.

25. Schwarz, S.; Kampchen, T.; Tilotta, M. C.; Gundisch, D.; Seitz, G. Synthesis and nicotinic binding studies on enantiopure pinnamine variants with an 8-azabicyclo[3.2.1]octane moiety. Pharmazie 2003, 58, 295-299.

26. Huber, C. S. The Crystal Structure and Absolute Configuration of 2,9-Diacetyl-9azabicyclo[4,2,1]non-2,3-ene. Acta Crystallogr. Ser. B. 1972, B28, 2577-2582.

27. Namikoshi, M.; Murakami, T.; Fujiwara, T.; Nagai, H.; Niki, T.; Harigaya, E.; Watanabe, M. F.; Oda, T.; Yamada, J.; Tsujimura, S. Biosynthesis and transformation of homoanatoxin-a in the cyanobacterium Raphidiopsis mediterranea Skuja and structures of three new homologues. Chem. Res. Toxicol. 2004, 17, 1692-1696.

28. Hemscheidt, T.; Rapala, J.; Sivonen, K.; Skulberg, O. M. Biosynthesis of Anatoxin-a in Anabaena-Flos-Aquae and Homoanatoxin-a in Oscillatoria-Formosa. J. Chem. Soc., Chem. Commun. 1995, 1361-1362.

29. Namikoshi, M.; Murakami, T.; Watanabe, M. F.; Oda, T.; Yamada, J.; Tsujimura, S.; Nagai, H.; Oishi, S. Simultaneous production of homoanatoxin-a, anatoxin-a, and a new non-toxic 4- 
hydroxyhomoanatoxin-a by the cyanobacterium Raphidiopsis mediterranea Skuja. Toxicon 2003, 42, 533-538.

30. Gallon, J. R.; Chit, K. N.; Brown, E. G. Biosynthesis of the Tropane-Related Cyanobacterial Toxin Anatoxin-a - Role of Ornithine Decarboxylase. Phytochemistry 1990, 29, 1107-1111.

31. Gallon, J. R.; Kittakoop, P.; Brown, E. G. Biosynthesis of Anatoxin-a by Anabaena-Flos-Aquae Examination of Primary Enzymatic Steps. Phytochemistry 1994, 35, 1195-1203.

32. Koskinen, A. M. P.; Rapoport, H. Synthetic and Conformational Studies on Anatoxin-a - a Potent Acetylcholine Agonist. J. Med. Chem. 1985, 28, 1301-1309.

33. Campbell, H. F.; Edwards, O. E.; Kolt, R. Synthesis of nor-Anatoxin-a and Anatoxin-a. Can. J. Chem. 1977, 55, 1372-1379.

34. Wegge, T.; Schwarz, S.; Seitz, G. A new and efficient synthetic route to enantiopure (+)-anatoxina from (-)-cocaine hydrochloride. Tetrahedron: Asymmetry 2000, 11, 1405-1410.

35. Zhang, C. M.; Lomenzo, S. A.; Ballay, C. J.; Trudell, M. L. An improved synthesis of (+)-2tropinone. J. Org. Chem. 1997, 62, 7888-7889.

36. Spivak, C. E.; Waters, J.; Witkop, B.; Albuquerque, E. X. Potencies and channel properties induced by semirigid agonists at frog nicotinic acetylcholine receptors. Mol. Pharmacol. 1983, 23, 337-343.

37. Badio, B.; Daly, J. W. Epibatidine, a potent analgesic and nicotinic agonist. Mol. Pharmacol. 1994, 45, 563-569.

38. Rozental, R.; Aracava, Y.; Scoble, G. T.; Swanson. K. L.; Wonnacott, S.; Albuquerque, E. X. Agonist recognition site of the peripheral acetylcholine receptor ion channel complex differentiates the enantiomers of nicotine. J. Pharmacol. Expt. Ther. 1989, 251, 395-404.

39. Wonnacott, S. Alpha-Bungarotoxin binds to low-affinity nicotine binding sites in rat brain. $J$. Neurochem. 1986, 47, 1706-1712.

40. Beers, W. H.; Reich, E. Structure and Activity of Acetylcholine. Nature 1970, 228, 917-923.

41. Sheridan, R. P.; Nilakantan, R.; Dixon, J. S.; Venkataraghavan, R. The Ensemble Approach to Distance Geometry - Application to the Nicotinic Pharmacophore. J. Med. Chem. 1986, 29, 899906.

42. Manallack, D.; Gallagher, T.; Livingstone, D. In Principles in QSAR and Drug Design; Devillers, J., Ed.; Academic Press: London, 1996; Vol. 2. pp 177-208.

43. Glennon, R. A.; Herndon, J. A.; Dukat, M. Epibatidine-Aided Studies toward Definition of a Nicotine Receptor Pharmacophore. Med. Chem. Res. 1994, 6, 465-486.

44. Tonder, J. E.; Olesen, P. H. Agonists at the alpha4beta2 nicotinic acetylcholine receptors: Structure-activity relationships and molecular modelling. Curr. Med. Chem. 2001, 8, 651-674.

45. Tonder, J. E.; Olesen, P. H.; Hansen, J. B.; Begtrup, M.; Pettersson, I. An improved nicotinic pharmacophore and a stereoselective CoMFA-model for nicotinic agonists acting at the central

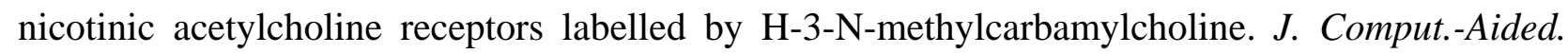
Mol. Des. 2001, 15, 247-258.

46. Tonder, J. E.; Hansen, J. B.; Begtrup, M.; Pettersson, I.; Rimvall, K.; Christensen, B.; Ehrbar, U.; Olesen, P. H. Improving the nicotinic pharmacophore with a series of (isoxazole)methylene-1azacyclic compounds: Synthesis, structure-activity relationship, and molecular modeling. J. Med. Chem. 1999, 42, 4970-4980. 
47. Glennon, R. A.; Dukat, M. alpha4beta2 nACh receptor pharmacophore models. Bioorg. Med. Chem. Lett. 2004, 14, 1841-1844.

48. Glennon, R. A.; Dukat, M.; Liao, L. Musings on alpha4beta2 nicotinic acetylcholine (nACh) receptor pharmacophore models. Curr. Med. Chem. 2004, 4, 631-644.

49. Manallack, D. T.; Ellis, D. D.; Thompson, P. E.; Gallagher, T.; Livingstone, D. J. Quantitative Structure-Activity Relationships of (+)-Anatoxin-a Derivatives. Natural Prod. Lett. 1994, 4, 121128.

50. Petersen, J. S.; Fels, G.; Rapoport, H. Chirospecific Syntheses of (+)-Anatoxin and (-)-Anatoxin-a. J. Am. Chem. Soc. 1984, 106, 4539-4547.

51. Sardina, F. J.; Howard, M. H.; Morningstar, M.; Rapoport, H. Enantiodivergent Synthesis of (+)Anatoxin and (-)-Anatoxin from L-Glutamic Acid. J. Org. Chem. 1990, 55, 5025-5033.

52. Sardina, F. J.; Howard, M. H.; Koskinen, A. M. P.; Rapoport, H. Chirospecific Synthesis of Nitrogen and Side-Chain Modified Analogs of (+)-Anatoxin. J. Org. Chem. 1989, 54, 4654-4660.

53. Howard, M. H.; Sardina, F. J.; Rapoport, H. Chirospecific Syntheses of Nitrogen and Side-Chain Modified Anatoxin Analogs - Synthesis of (1R)-Anatoxinal and (1R)-Anatoxinic AcidDerivatives. J. Org. Chem. 1990, 55, 2829-2838.

54. Costa, A. C.; Swanson, K. L.; Aracava, Y.; Aronstam, R. S.; Albuquerque, E. X. Molecular effects of dimethylanatoxin on the peripheral nicotinic acetylcholine receptor. J. Pharmacol. Exp. Ther. 1990, 252, 507-516.

55. Kofuji, P.; Aracava, Y.; Swanson, K. L.; Aronstam, R. S.; Rapoport, H.; Albuquerque, E. X. Activation and blockade of the acetylcholine receptor-ion channel by the agonists (+)-anatoxin-a, the N-methyl derivative and the enantiomer. J. Pharmacol. Exp. Ther. 1990, 252, 517-525.

56. Wonnacott, S.; Jackman, S.; Swanson, K. L.; Rapoport, H.; Albuquerque, E. X. Nicotinic pharmacology of anatoxin analogs: II. Side chain structure-activity relationships at neuronal nicotinic ligand binding sites. J. Pharmacol. Exp. Ther. 1991, 259, 387-391.

57. Stevens, D. K.; Krieger, R. I. N-Methylation of anatoxin-a abolishes nicotinic cholinergic activity. Toxicon. 1990, 28, 133-134.

58. Swanson, K. L.; Aronstam, R. S.; Wonnacott, S.; Rapoport, H.; Albuquerque, E. X. Nicotinic pharmacology of anatoxin analogs. I. Side-chain structure-activity relationships at peripheral agonist and noncompetitive antagonist sites. J. Pharmacol. Exp. Ther. 1991, 259, 377-386.

59. Arneric, S. P.; Sullivan, J. P.; Briggs, C. A.; Donnelly-Roberts, D.; Anderson, D. J.; Raszkiewicz, J. L.; Hughes, M. L.; Cadman, E. D.; Adams, P.; Garvey, D. S. et al. (S)-3-methyl-5-(1-methyl-2pyrrolidinyl)isoxazole (ABT 418): a novel cholinergic ligand with cognition-enhancing and anxiolytic activities: I. In vitro characterization. J. Pharmacol. Exp. Ther. 1994, 270, 310-318.

60. Thomas, P.; Brough, P. A.; Gallagher, T.; Wonnacott, S. Alkyl-Modified Side-Chain Variants of Anatoxin-a - a Series of Potent Nicotinic Agonists. Drug Dev. Res. 1994, 31, 147-156.

61. Parsons, P. J.; Camp, N. P.; Edwards, N.; Sumoreeah, L. R. Synthesis of (+/-)-Anatoxin-a and Analogues. Tetrahedron 2000, 56, 309-315.

62. Huby, N. J. S.; Thompson, P.; Wonnacott, S.; Gallagher, T. Structural Modification of Anatoxin-a - Synthesis of Model Affinity Ligands for the Nicotinic Acetylcholine-Receptor. J. Chem. Soc., Chem. Commun. 1991, 243-245. 
63. Magnus, N. A.; Ducry, L.; Rolland, V.; Wonnacott, S.; Gallagher, T. Direct C-11 functionalisation of anatoxin-a. Application to the synthesis of new ligand-based structural probes. J. Chem. Soc., Perkin Trans. 1 1997, 2313-2318.

64. Thompson, P. E.; Manallack, D. T.; Blaney, F. E.; Gallagher, T. Conformational Studies on (+)Anatoxin-a and Derivatives. J. Comput.-Aided Mol. Des. 1992, 6, 287-298.

65. Hacksell, U.; Mellin, C. Stereoselectivity of Nicotinic Receptors. Prog. Brain Res. 1989, 79, 95100.

66. Kanne, D. B.; Ashworth, D. J.; Cheng, M. T.; Mutter, L. C.; Abood, L. G. Synthesis of the First Highly Potent Bridged Nicotinoid - 9-Azabicyclo[4.2.1]nona[2,3-c]pyridine (Pyrido[3,4b]homotropane). J. Am. Chem. Soc. 1986, 108, 7864-7865.

67. Kanne, D. B.; Abood, L. G. Synthesis and Biological Characterization of Pyridohomotropanes Structure-Activity-Relationships of Conformationally Restricted Nicotinoids. J. Med. Chem. 1988, 31, 506-509.

68. Gundisch, D.; Kampchen, T.; Schwarz, S.; Seitz, G.; Siegl, J.; Wegge, T. Syntheses and evaluation of pyridazine and pyrimidine containing bioisosteres of (+/-)-pyrido[3.4b]homotropane and pyrido[3.4-b]tropane as novel nAChR ligands. Bioorg. Med. Chem. 2002, 10, 1-9.

69. Brough, P. A.; Gallagher, T.; Thomas, P.; Wonnacott, S.; Baker, R.; Malik, K. M. A.; Hursthouse, M. B. Synthesis and X-Ray Crystal-Structure of 2-Acetyl-9-Azabicyclo[4.2.1]nonan-3-one - a Conformationally Locked s-Cis Analog of Anatoxin-a. J. Chem. Soc., Chem. Commun. 1992, 1087-1089.

70. Hernandez, A.; Rapoport, H. Conformationally Constrained Analogs of Anatoxin - Chirospecific Synthesis of s-Trans Carbonyl Ring-Fused Analogs. J. Org. Chem. 1994, 59, 1058-1066.

71. Holladay, M. W.; Dart, M. J.; Lynch, J. K. Neuronal nicotinic acetylcholine receptors as targets for drug discovery. J. Med. Chem. 1997, 40, 4169-4194.

72. Le Novere, N.; Grutter, T.; Changeux, J. P. Models of the extracellular domain of the nicotinic receptors and of agonist- and $\mathrm{Ca}^{2+}$-binding sites. Proc. Natl. Acad. Sci. U S A. 2002, 99, 32103215.

73. Wright, E.; Gallagher, T.; Sharples, C. G. V.; Wonnacott, S. Synthesis of UB-165: A novel nicotinic ligand and anatoxin-a/epibatidine hybrid. Bioorg. Med. Chem. Lett. 1997, 7, 2867-2870.

74. Sharples, C. G.; Kaiser, S.; Soliakov, L.; Marks, M. J.; Collins, A. C.; Washburn, M.; Wright, E.; Spencer, J. A.; Gallagher, T.; Whiteaker, P.; Wonnacott, S. UB-165: a novel nicotinic agonist with subtype selectivity implicates the alpha4beta2* subtype in the modulation of dopamine release from rat striatal synaptosomes. J. Neurosci. 2000, 20, 2783-2791.

75. Cao, Y. J.; Surowy, C. S.; Puttfarcken, P. S. Nicotinic acetylcholine receptor-mediated [3H]dopamine release from hippocampus. J. Pharmacol. Exp. Ther. 2005, 312, 1298-1304.

76. Sharples, C. G. V.; Karig, G.; Simpson, G. L.; Spencer, J. A.; Wright, E.; Millar, N. S.; Wonnacott, S.; Gallagher, T. Synthesis and pharmacological characterization of novel analogues of the nicotinic acetylcholine receptor agonist (+/-)-UB-165. J. Med. Chem. 2002, 45, 3235-3245.

77. Gohlke, H.; Gundisch, D.; Schwarz, S.; Seitz, G.; Tilotta, M. C.; Wegge, T. Synthesis and nicotinic binding studies on enantiopure diazine analogues of the novel (2-chloro-5-pyridyl)-9azabicyclo[4.2.1]non-2-ene UB-165. J. Med. Chem. 2002, 45, 1064-1072. 
78. Karig, G.; Large, J. M.; Sharples, C. G. V.; Sutherland, A.; Gallagher, T.; Wonnacott, S. Synthesis and nicotinic binding of novel phenyl derivatives of UB-165. Identifying factors associated with alpha7 selectivity. Bioorg. Med. Chem. Lett. 2003, 13, 2825-2828.

79. Sutherland, A.; Gallagher, T.; Sharples, C. G. V.; Wonnacott, S. Synthesis of two fluoro analogues of the nicotinic acetylcholine receptor agonist UB-165. J. Org. Chem. 2003, 68, 2475-2478.

Samples Availability: Not available.

(C) 2006 by MDPI (http://www.mdpi.org). Reproduction is permitted for noncommercial purposes. 